\title{
Bennett on Parts Twice Over
}

DOI:

10.1007/s11406-012-9396-z

\section{Document Version}

Submitted manuscript

Link to publication record in Manchester Research Explorer

\section{Citation for published version (APA):}

Fisher, A. R. J. (2013). Bennett on Parts Twice Over. Philosophia, 41(3), 757-761. https://doi.org/10.1007/s11406012-9396-z

\section{Published in:}

Philosophia

\section{Citing this paper}

Please note that where the full-text provided on Manchester Research Explorer is the Author Accepted Manuscript or Proof version this may differ from the final Published version. If citing, it is advised that you check and use the publisher's definitive version.

\section{General rights}

Copyright and moral rights for the publications made accessible in the Research Explorer are retained by the authors and/or other copyright owners and it is a condition of accessing publications that users recognise and abide by the legal requirements associated with these rights.

\section{Takedown policy}

If you believe that this document breaches copyright please refer to the University of Manchester's Takedown Procedures [http://man.ac.uk/04Y6Bo] or contact uml.scholarlycommunications@manchester.ac.uk providing relevant details, so we can investigate your claim.

\section{OPEN ACCESS}




\title{
Bennett on Parts Twice Over
}

\author{
A. R. J. FISHER
}

In this paper I outline the main features of Karen Bennett's (2011) non-classical mereology, and identify its methodological costs. I argue that Bennett's mereology cannot account for the composition of structural universals because it cannot explain the mereological difference between isomeric universals, such as being butane and being isobutane. I consider responses, which come at costs to the view.

Karen Bennett (2011) presents a non-classical system of mereology based on a distinction between entities having 'parthood slots' and entities having parts that occupy 'parthood slots'. 'One thing is part of another just in case it fills one of that thing's parthood slots' (Bennett 2011: 1). Call this novel and innovative system, slotmereology.

Slot-mereology differs from classical extensional mereology (hereafter CEM) by taking two predicates as primitive - '... is a parthood slot of ...' and '... fills ...' where CEM takes only one as primitive, i.e., either '... is (a) part of ...' or '... is a proper part of ...'. Taking a 'slot' and 'fills' predicate as primitive allows Bennett to define up the predicates 'part' and 'proper part' as follows:

Parthood: $x$ is part of $y$ iff $x$ fills one of $y$ 's parthood slots (2011: 9). ${ }^{1}$

Proper Parthood: $x$ is a proper part of $y$ iff $x$ is part of $y$ but $y$ is not part of $x$ $(2011: 9)^{2}$

On this view, parts of objects fill slots (and only slots), slots do not have slots, and slots cannot be fillers of slots. Bennett then introduces a set of axioms that form the basis of slot-mereology (see (2011: $\$ 6)$ ). Two axioms are of interest:

(A6) Mutual Occupancy is Identity: $\left(\mathrm{P}_{\mathrm{s}} z_{1} y \& \mathrm{~F} x z_{1}\right) \&\left(\mathrm{P}_{\mathrm{s}} z_{2} x \& \mathrm{~F} y z_{2}\right) \rightarrow x=y$ (2011: 11)

(A8) Slot Strong Supplementation: $\exists z \mathrm{P}_{\mathrm{s}} z x \& \exists z \mathrm{P}_{\mathrm{s}} z y \rightarrow\left(\sim\left(\exists z \mathrm{P}_{\mathrm{s}} z x \&\right.\right.$ F $\left.y z\right) \rightarrow$ $\left.\exists z\left(\mathrm{P}_{\mathrm{s}} z y \& \sim \mathrm{P}_{\mathrm{s}} z x\right)\right)(2011: 14)$

The first axiom says informally that if $x$ and $y$ fill each other's parthood slots (i.e., $z_{2}$ and $z_{1}$ respectively), then $x$ and $y$ are identical. The second tells us that supposing $x$ and $y$ have slots, if there is no slot of $x$ that $y$ fills, then there is a slot of $y$ which is not

\footnotetext{
${ }^{1}$ In slot-mereology ' $x$ is a parthood slot of $y$ ' is formally written as ' $\mathrm{P}_{S} x y$ ' and ' $x$ fills $y$ ' as 'Fxy'.

${ }^{2}$ Proper parthood is formally written as 'PP $x y$ '.
} 
a slot of $x$. This axiom is intended to resemble the Strong Supplementation axiom of CEM: 'if $y$ is not a part of $x$, then $y$ has a part $z$ that is neither part of $x$ nor such that $x$ is part of it' (2011: 13).

The axioms and definitions of slot-mereology yield various theorems, two of which are significant for what follows. Given Parthood and (A6) we can derive the familiar:

(T8) Anti-Symmetry: (Pxy \& Pyx) $\rightarrow x=y$ (2011: 12)

This theorem along with (A8) gives us:

(T14) Slot Extensionality: $(\exists z \mathrm{PP} z x \vee \exists z \mathrm{PP} z y) \rightarrow\left(x=y \leftrightarrow \exists z\left(\mathrm{PP}_{\mathrm{s}} z x \leftrightarrow \mathrm{PP}_{\mathrm{s}} z y\right)\right)$ $(2011: 15)^{3}$

Less formally Slot Extensionality tells us that 'composite objects are identical just in case they have exactly the same proper parthood slots' (2011: 15). As the name suggests, (T14) resembles the well-discussed Extensionality axiom of CEM and is supposed to capture the intuition that entities made of the same parts are identical. In fact, Bennett is clear that she wants slot-mereology to capture the intuitions of CEM but 'in a different way' (2011: 14).

Overall, slot-mereology is supposed to capture the thought that there is more to composite entities than their parts. Slot-mereology teaches us that the mereological structure of an object is not exhausted by its parts. Further mereological structure is to be found in the slots that objects have. The source of the explanatory power of slotmereology comes from the fact that it is advertised as a unified account of composite objects. It is said to apply not only to ordinary material objects but also structural universals and states of affairs.

In what follows, I discuss the ideological and conceptual costs of slot-mereology and argue that slot-mereology cannot explain the mereological difference between isomeric universals such as being butane and being isobutane. I then consider responses to this objection, which I argue come at costs to slot-mereology.

Every theory has ideological costs insofar as every theory has primitives. When comparing slot-mereology with CEM, it seems slot-mereology has an extra primitive, assuming predicate calculus with identity is held fixed. I take this extra primitive to be a further ideological cost of slot-mereology. According to Quine (1951: 14), the ideology is whatever 'ideas' are expressed in the theory using devices of expression such as predicates or operators. For our purposes, it is the predicates or operators of the theory and not the 'ideas' that are of significance. Ideological parsimony tells us that as a

3 ' $\mathrm{PP}_{s} x y$ ' is Proper Parthood Slot: ' $x$ is a proper parthood slot of $y$ just in case $x$ is a parthood slot of $y$ that $y$ does not fill' (2011: 9). See Bennett's (2011: 15, n. 26) derivation for technical details. 
general rule we ought to reduce the number of primitives in our theory. Do not postulate ideological primitives more than necessary, we might say. In comparing CEM with slot-mereology, it follows that (ceteris paribus) the extra primitive is a prima facie reason to reject slot-mereology. If we do not have an argument that defeats this prima facie reason, we ought to reject slot-mereology.

Furthermore, by introducing two new primitive terms, slot-mereology introduces the concept of a 'parthood slot' and 'filler'. At first glance, this is counter-intuitive in the following sense. Ordinary examples of wholes and their parts such as the parts of this stapler and the pieces of that French silk pie do not, intuitively speaking, involve any notion of a 'slot' which a particular part 'fills' when part of something else. The basic concept at work here is simply 'part' and no further notion is needed to understand the given examples. CEM takes the more basic concept of 'part' (or 'proper part') as primitive in virtue of taking '... is (a) part of ...' as a primitive predicate in its ideology. But given that slot-mereology takes 'slot' and 'fills' as primitive, the common-sense notion of 'part' comes out as conceptually derivative.

The added conceptual complexity that is at the core of slot-mereology, I say, counts as a conceptual cost against the view. We ought to prefer theories that intuitively represent ordinary cases in such a way that they employ a limited number of basic concepts; perhaps concepts that are basic to our conceptual scheme. This conceptual cost however is up for negotiation. It is something that can be bargained for in light of slot-mereology yielding an explanatory gain over competing theories.

A major part of Bennett's motivation for introducing slot-mereology is to provide a response to David Lewis' (1986) objection against the isomorphic variant of the pictorial conception of structural universals (2011:2). Lewis argued that, according to this particular conception, some structural universals such as the now hackneyed example of being methane have the same part several times over. Being methane taken as an 'individual' isomorphic to its instances has not only being bydrogen but also bonded four times over. However, given that 'a universal is one, not many' (Armstrong 1978: 69-70), it is unintelligible to say that being bydrogen is a part four times over of being methane. Therefore, this particular conception of structural universals is inconsistent (see (Lewis 1986: 34)).

One response you might consider is to simply reject this variant of the pictorial conception of structural universals and provide another account of structural universals altogether. But Bennett provides what I think is a more direct response that accepts this conception of structural universals and instead shows how an object can have the same part multiple times over. Slot-mereology explains how structural universals have their parts multiple times over in virtue of their slots being occupied by fillers. Consider being methane. It has as parts being bydrogen and the dyadic universal bonded four times over, and being carbon once. But it also has nine slots, four of 
which are filled by being hydrogen, four of which are filled by bonded and the remainder filled by being carbon. Thus, what it is for a thing to have a part multiple times over is made intelligible and the particular conception of structural universals rendered consistent.

Bennett thinks this is an adequate response that D. M. Armstrong should adopt in the face of Lewis' objection. In other words Bennett thinks slot-mereology 'will do what Armstrong needs' (2011: 20). But, if slot-mereology cannot account for the composition of structural universals, then it cannot provide an adequate response to Lewis' objection. Slot-mereology cannot account for the composition of structural universals as it cannot explain the mereological difference between isomeric universals such as being butane and being isobutane.

The objection is as follows. Consider being methane and being butane. Both structural universals have being bydrogen and being carbon as parts but in different ways. The difference between the two universals is in their mereological structure. As Bennett writes, '[t]hey differ in mereological structure, rather than in the entities that do the parthood work' (2011: 20). Since the number of slots had by being methane is distinct from the number of slots had by being butane, the universals are distinct.

Notice that being butane has being bydrogen ten times over, being carbon four times over, and bonded thirteen times over. It therefore has twenty-seven parthood slots, each filled by its respective universal. But being isobutane also has being hydrogen ten times over, being carbon four times over, and bonded thirteen times over. Therefore, it also has twenty-seven parthood slots. Given Slot Extensionality (T14), 'composite objects are identical just in case they have exactly the same proper parthood slots' (2011: 15). Therefore, being isobutane and being butane are identical. However this is the incorrect result (cf. (Lewis 1986: 38)). To see this, consider the isobutane stored in the back of that chemist's fridge and the butane stored in my lighter. The molecules in each case instantiate different structural universals. Therefore, being butane and being isobutane are distinct universals; but according to slotmereology they are identical given that they have the same number of slots.

One response to this objection is to say that structural universals are identical just in case they have the same number of slots arranged in the same way. Thus, being butane and being isobutane are distinct since their slots are arranged in different ways. However, I find this response unconvincing since it introduces a requirement which depends on postulating some further relation or ordering between the slots of structural universals. Such a move undermines the extensionalist spirit of (T14). Since Bennett argues that (T14) is required to measure mereological differences in terms of slots or slothood, it seems we cannot appeal to some further relation or ordering to account for differences between isomeric universals. Furthermore, recall that part of Bennett's project is to not reject the axioms of CEM that cause trouble in certain cases. Rather she 
hopes to mimic the principles of CEM and capture the intuitions of the classical mereologist. Therefore, such a response would undermine this project because it wouldn't be in the spirit of slot-mereology following the letter of CEM.

A second response to this objection involves rejecting (A6) and/or (A8). But rejecting either (A6) or (A8) has disastrous consequences. If we reject (A6) Mutual Occupancy is Identity, we will be unable to derive (T8) Anti-Symmetry since (T8) is more or less equivalent to (A6). If we reject (T8), we must reject the widely-accepted idea that parthood is a partial ordering. But I take this move as too extreme. If we reject (A8), we must reject (T13) Slot Weak Supplementation: PP $x y \rightarrow \exists z\left(\mathrm{P}_{s} z y \& \sim \mathrm{P}_{s} z x\right)$ as it derives from (A8) and Parthood (see (2011: 15)). Denying (T13) would be tantamount to rejecting what is definitive of the very concept of part, as Bennett correctly notes (2011: 14). Hence, this move is also too extreme.

As a final response we may consider modifying (A8) in order to derive a theorem distinct from (T14). But I think this will fail to capture the intuition of extensionality. As noted above one of the attractive features of slot-mereology is its ability to mimic and not slaughter the intuitions encapsulated in CEM. Thus, I conclude that denying or modifying either axiom is not an adequate response to the objection from isomeric universals. Therefore, slot-mereology cannot account for the mereological difference between isomeric universals. ${ }^{4}$

\section{References}

Armstrong, D. M. 1978. Universals and Scientific Realism II: A Theory of Universals. Cambridge: Cambridge University Press.

Bennett, Karen. 2011. Having a Part Twice Over. Australasian Journal of Philosophy DOI: 10.1080/00048402.2011.637936 (iFirst article): 1-21.

Lewis, David. 1986. Against Structural Universals. Australasian Journal of Philosophy 64/1: 25-46.

Quine, W. V. 1951. Ontology and Ideology. Philosophical Studies 2/1: 11-15.

\footnotetext{
${ }^{4}$ Thanks to Peter Forrest and André Gallois for helpful comments and discussion.
} 